\title{
OCORRÊNCIA DE Campylobacter EM GRANJAS E ABATEDOURO AVÍCOLAS NA MESORREGIÃO METROPOLITANA DE BELÉM, PA, BRASIL
}

\author{
Sílvio Orlan de Castro Chaves, ${ }^{1}$ Cyntia Oliveira de Souza, ${ }^{2}$ José de Arimatéia Freitas, ${ }^{3}$ \\ Dolores Dias dos Santos, ${ }^{2}$ Cláudio Vieira de Araújo ${ }^{4}$ e René Ribeiro da Silva ${ }^{1}$ \\ 1. Laboratório de Diagnóstico Bacteriológico e Parasitológico MAPA, Lanagro, PA. \\ E-mail: silvio.chaves@agricultura.gov.br \\ 2. Seção de Bacteriologia e Micologia, Instituto Evandro Chagas, IEC \\ 3. Universidade Federal Rural da Amazônia, UFRA \\ 4 . professor adjunto da Universidade Federal de Mato Grosso - Campus de Sinop
}

\section{RESUMO}

Com o objetivo de verificar a ocorrência de Campylobacter em granjas e abatedouro avícolas, foram coletadas, em três granjas avícolas, 120 amostras de swab cloacal $(\mathrm{n}=30)$, de cama de frango $(n=30)$, de ração $(n=30)$ e de água dos bebedouros $(n=30)$. Também colheram-se, em um abatedouro, 126 amostras de água $(n=36)$, de pele do conjunto peito/pescoço $(\mathrm{n}=30)$, de fígado $(\mathrm{n}=30)$ e de moela $(\mathrm{n}=30)$. Isolou-se Campylobacter em 40 (33,3\%) amostras das granjas. Em análise das frequências dos isolados de Campylobacter nas granjas, observou-se que $29(96,6 \%)$ amostras de $s w a b$ cloacal, dez $(33,3 \%)$ amostras de cama e uma (3,3\%) amostra de água foram positivas para Campylobacter. Identifiou-se Campylobacter jejuni em $33(82,5 \%)$ cepas isoladas nas granjas. No abatedouro, as onze $(8,73 \%)$ cepas isoladas foram identificadas como $C$. jejuni. Em análise das frequências dos isolados de $C$. jejuni no abatedouro, observou-se que dez $(27,8 \%)$ amostras de água provenientes da calha de evisceração foram positivas para $C$. jejuni, seguida pela moela, com uma $(3,3 \%)$ amostra positiva. As principais fontes de contaminação nas granjas foram as fezes, a cama e, em menor escala, a água. Os principais pontos críticos observados no abatedouro foram a água proveniente da calha de evisceração, seguida pela moela coletada no minitanque de resfriamento.

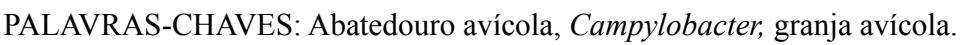

\section{OCCURRENCE OF Campylobacter IN CHICKEN FARMS AND SLAUGTHERHOUSE AT THE METROPOLITAN REGION OF BELÉM, PA, BRAZIL}

The aim of the present study was to observe the occurrence of Campylobacter in chicken farms and in a slaughterhouse. A total of 120 samples were collected in three chicken farms: cloacal swabs $(n=30)$, poultry litter $(n=30)$, feed $(n=30)$ and water $(n=30)$ samples. In the slaughterhouse, 126 samples were collected: water samples $(n=36)$, neck and chest skins $(n=30)$, livers $(n=30)$ and gizzards $(\mathrm{n}=30)$. Campylobacter was isolated in $40(33.33 \%)$ chicken farm samples: 29 (96.6\%) cloacal swabs, ten $(33.3 \%)$ poultry litter and one $(3.3 \%)$ water sample. Campylobacter je- juni was identified in $33(82.5 \%)$ strains from chicken farms. In the slaugtherhouse, all the eleven $(8.73 \%)$ isolated strains were identified as $C$. jejuni: ten (27.8\%) water samples and one (3.3\%) gizzard sample. The main contamination sources in chicken farms were the cloacal swabs, the poultry litter and, in small proportion, the water. In the slaughterhouse, the main critical points were the water from poultry evisceration and the gizzard collected from the small cooling tank.

KEY WORDS: Campylobacter, chicken farm, slaughterhouse. 


\section{INTRODUÇÃO}

As zoonoses que ocorrem com maior frequência nos países industrializados são as infecções de origem alimentar, causadas por espécies dos gêneros Salmonella e Campylobacter, sendo os principais patógenos associados aos produtos de origem avícola (BRYAN \& DOYLE, 1995).

Alta densidade populacional no criatório e as elevadas taxas de abate, dado que as carcaças permanecem muito próximas umas das outras, estão entre os fatores que contribuem para o aumento da contaminação da carne de frango. Isso porque tais condições favorecem uma rápida disseminação de qualquer patógeno que possa ter acesso ao criatório (MEAD, 2004).

As principais espécies que acometem o homem, demais mamíferos e os pássaros são C. jejuni e C. coli. As aves, geralmente, são assintomáticas. Evidências epidemiológicas têm sugerido os produtos de origem animal, especialmente os produtos avícolas, como principal veículo para infecção humana (SALEHA et al., 1998).

De acordo com BAILEY (1993), as principais fontes de contaminação das aves são: a ração contaminada, a transmissão horizontal e o ambiente de criação contaminado, envolvendo vetores como roedores, insetos, pássaros silvestres, animais domésticos e o homem.

Entre $30 \%$ e $100 \%$ das aves transportam Campylobacter no intestino. Durante as etapas de abate, as carcaças e as vísceras comestíveis podem ser contaminadas com o material fecal e o agente pode ser detectado no produto acabado e pronto para o consumo (CARVALHO, 1998).

A depenação e a evisceração têm sido mencionadas como pontos críticos na contaminação cruzada das carcaças durante o abate e, eventualmente, a contaminação pode ser disseminada através do equipamento, mãos dos manipuladores, pelo ar, luvas e utensílios (MACHADO et al., 1994).

As infecções de origem alimentar, causadas por Campylobacter, resultam em grandes perdas econômicas e estão relacionadas à produção e abate de frangos, etapas importantes na disseminação dessas bactérias para o homem. Portanto, linhas de pesquisas envolvendo a cadeia de produção avícola são fundamentais para que medidas de profilaxia e de controle possam ser adotadas (HARTNETT et al., 2002).

O objetivo deste trabalho foi verificar a ocorrência de Campylobacter em granjas e abatedouro avícolas localizados na mesoregião metropolitana de Belém, Pará, identificando-se as fontes de contaminação no criatório e os pontos críticos durante o abate.

\section{MATERIAL E MÉTODOS}

As amostras foram coletadas em três granjas avícolas e em um abatedouro de frangos, localizados na mesorregião metropolitana de Belém, Pará, entre os meses de janeiro e maio de 2007. Nessa região há 180 granjas e dois abatedouros oficiais. No período em que foram realizadas as coletas das amostras, foram abatidas, no estado do Pará, 12.595.422 aves, sendo a região em estudo responsável por $44 \%$ da produção estadual. Colheram-se, nas granjas, amostras oriundas de água do bebedouro ( $\mathrm{n}=30)$, de $s w a b$ cloacal $(\mathrm{n}=30)$, de ração $(n=30)$ e de cama de frango $(n=30)$, perfazendo um total de 120 amostras nas três granjas estudadas. Para a identificação de pontos críticos no abatedouro, colheram-se amostras de água $(\mathrm{n}=36)$ em doze pontos diferentes da linha de abate, amostras de pele do conjunto peito/pescoço $(n=30)$, fígado $(n=30)$ e moela $(n=30)$, totalizando 126 amostras. As amostras de água do abatedouro eram provenientes da escaldadeira, das calhas de evisceração e dos tanques e minitanques de resfriamento.

Colheram-se as amostras cloacais por meio de swabs estéreis diretamente das cloacas de frangos de corte e imediatamente depositadas em tubos contendo $5 \mathrm{~mL}$ de caldo tioglicolato $\mathrm{pH} \mathrm{7,2}$ e mantidas em temperatura de $5^{\circ} \mathrm{C}$ por doze horas. As amostras de cama e de ração foram colhidas e acondicionadas em sacos plásticos estéreis, sendo imediatamente transportadas ao laboratório e, em seguida, pesadas. Para cada cinco gramas das amostras, adicionaram-se $45 \mathrm{~mL}$ de caldo tioglicolato $\mathrm{pH} 7,2$, as quais foram mantidas por doze horas à temperatura de $5^{\circ} \mathrm{C}$ (CARVALHO et al., 2001).

As amostras de pele do conjunto peito/pescoço, fígado e moela foram transportadas sob refrigeração e trituradas no laboratório com auxílio de pinça e tesoura esterilizadas. Em seguida, colocaram-se 25 gramas de cada amostra em $225 \mathrm{~mL}$ de caldo tioglicolato $\mathrm{pH} 7,2$, mantendo-se-as por doze horas à temperatura de $5^{\circ} \mathrm{C}$ (CARVALHO et al., 2001). 
As amostras de água da granja e do abatedouro foram colhidas em volume de $500 \mathrm{~mL}$ e mantidas em caixas isotérmicas com gelo e processadas imediatamente após a chegada ao laboratório. Adicionaram-se 2,5 mL de tiosulfato de sódio ao frasco coletor de água antes da coleta (HUNT et al., 2001).

Para o isolamento, aplicaram-se membranas filtrantes de 0,45 $\mu \mathrm{m}$ de porosidade (SCOTTER et al., 1993; PILET et al., 1997) sobre placas com meio seletivo para Campylobacter composto por ágar brucella adicionado de suplemento FBP $(0,025 \%$ de sulfato ferroso, $0,025 \%$ de piruvato de sódio e $0,025 \%$ de metabissulfito de sódio) e $7 \mathrm{~mL}$ de sangue desfibrinado e estéril de carneiro em $100 \mathrm{~mL}$ do meio básico (ágar brucella) com pH final 7,2 (KONEMAN et al., 2001).

Decorrido o período de doze horas à temperatura de $5^{\circ} \mathrm{C}$, cerca de dez gotas do caldo das amostras cloacais, da cama, ração, pele do conjunto peito/pescoço, fígado e moela foram depositadas sobre a membrana filtrante. Um total de $100 \mathrm{~mL}$ de cada amostra de água foi centrifugado a 7.000 r.p.m. durante quinze minutos. O sedimento e mais $2 \mathrm{~mL}$ do sobrenadante foram homogeneizados e, em seguida, instilaram-se cerca de dez gotas na membrana filtrante contida sobre o meio de isolamento seletivo. Após trinta minutos, as membranas foram retiradas e as placas incubadas a $42^{\circ} \mathrm{C}$ por
48-72 horas, em jarras para cultivo em anaerobiose com atmosfera de microaerofilia: $5 \%$ de $\mathrm{O}_{2}, 10 \%$ de $\mathrm{CO}_{2}$ e $85 \%$ de $\mathrm{N}_{2}$ (PILET et al., 1997; HUNT, 2001).

As colônias típicas ou suspeitas do gênero foram identificadas por meio de morfologia microscópica, pela coloração de Gram, motilidade em microscópio de campo escuro, reações de catalase e de oxidase. Para identificação bioquímica das espécies, realizaram-se os testes de redução de nitrato, produção de $\mathrm{H}_{2} \mathrm{~S}$ em TSI (Tríplice Sugar Iron), hidrólise de hipurato e resistência ao ácido nalidíxico e à cefalotina (HUNT et al., 2001;).

Foi empregado o teste do qui-quadrado $\left(\chi^{2}\right)$ de contigência para comparação dos resultados entre as diferentes granjas, entre tipos diferentes de amostras nas granjas, entre as amostras do abatedouro e entre os isolados de C. jejuni e Campylobacter, adotando-se como nível de significância o valor de 0,05 (SAS, 1993).

\section{RESULTADOS E DISCUSSÃO}

A Tabela 1 apresenta os resultados da pesquisa de Campylobacter em diferentes amostras provenientes de três granjas.

A Tabela 2 sumariza os resultados da pesquisa de Campylobacter nas amostras de swab cloacal, cama, ração e água das três granjas pesquisadas.

TABELA 1. Frequência de isolamento de Campylobacter nas granjas 1,2 e 3

\begin{tabular}{ccccccc}
\hline Granjas & \multicolumn{2}{c}{ Negativo } & \multicolumn{2}{c}{ Positivo } & \multicolumn{2}{c}{ Total } \\
\hline & $\mathrm{n}$ & $\%$ & $\mathrm{~N}$ & $\%$ & $\mathrm{n}$ & \multicolumn{2}{c}{ \% } \\
\hline 1 & 26 & 21,67 & 14 & 11,67 & 40 & 33,33 \\
2 & 26 & 21,67 & 14 & 11,67 & 40 & 33,33 \\
3 & 28 & 28,33 & 12 & 10,00 & 40 & 33,33 \\
Total & 80 & 66,67 & 40 & 33,33 & 120 & 100,00 \\
\hline
\end{tabular}

$\chi^{2}=0,30(p>0,05)$

TABELA 2. Frequência de isolados de Campylobacter em cada tipo de amostra coletada em três granjas avícolas

\begin{tabular}{lccc}
\hline Tipo de amostra & Número de amostras & Positivo N & Amostras positivas (\%) \\
\hline Swab cloacal & 30 & 29 & 96,7 \\
Cama & 30 & 10 & 33,3 \\
Ração & 30 & 0 & 0,0 \\
Água & 30 & 1 & 3,3 \\
Total & 120 & 40 & 33,3 \\
\hline
\end{tabular}

$\chi 2=81,30(p<0,0001)$ 
Quanto à identificação das espécies de Campylobacter nas três granjas pesquisadas, $33(82,50 \%)$ cepas foram identificadas bioquimicamente como $C$. jejuni e em sete $(17,50 \%)$ cepas isoladas não foi possível definir a espécie (Tabela 3 ).

Todas as cepas isoladas no abatedouro foram identificadas bioquimicamente como $C$. jejuni. Isolou- se C. jejuni nas amostras de água das calhas de evisceração, não sendo isolada a bactéria nas amostras de água da escaldadeira e dos tanques e minitanques de resfriamento. Os resultados dos isolamentos de Campylobacter no abatedouro podem ser observados na Tabela 4.

TABELA 3. Frequência de isolamento de Campylobacter em amostras procedentes de três granjas avícolas, segundo a espécie identificada

\begin{tabular}{cccc}
\hline \multirow{2}{*}{ Espécie } & \multicolumn{3}{c}{ Resultados } \\
\cline { 2 - 4 } & $\mathrm{N}$ & 82,50 \\
\hline Campylobacter jejuni & 33 & 17,50 \\
Campylobacter spp*. & 7 & 100,00 \\
Total & 40 & & $\%$ \\
\hline
\end{tabular}

$\chi 2=13,33(p<0,05) *$ Espécie não identificada.

TABELA 4. Frequência dos isolados de $C$. jejuni em cada tipo de amostra colhida em abatedouro avícola

\begin{tabular}{lccc}
\hline Tipo de amostra & Número de amostras & Positivo & Amostras positivas (\%) \\
\hline Fígado & 30 & 0 & 0,0 \\
Moela & 30 & 1 & 3,3 \\
Pele (peito/ pescoço) & 30 & 0 & 0,0 \\
Água & 36 & 10 & 27,8 \\
Total & 126 & 11 & 8,7 \\
\hline
\end{tabular}

$\chi 2=85,84(p<0,0001)$

O isolamento de Campylobacter em quarenta $(33,33 \%)$ amostras procedentes das granjas (Tabelas 1 e 2) foi superior aos resultados encontrados por CARVALHO et al. (2001), que isolaram a bactéria em apenas 5,60\% das amostras de duas granjas avícolas na região de Ribeirão Preto, SP.

Não houve diferença significativa $(p>0,05)$ entre o número de isolados positivos das três diferentes granjas (Tabela 1), provavelmente pelo fato de os três estabelecimentos apresentarem semelhantes sistemas de manejos, aves e insumos provenientes da mesma fonte.

Observa-se na Tabela 2 que, entre as trinta amostras de $s w a b$ cloacal, 29 (96,7\%) foram positivas para Campylobacter. Elevadas taxas de isolamento de
Campylobacter em amostras de fezes de frango foram também demonstradas por outros autores. Assim, EVANS \& SAYERS (2000) isolaram o microrganismo em $91 \%$ das amostras de swab cloacal de frangos da Grã-Bretanha e RODRIGO et al. (2005) isolaram Campylobacter em $78,8 \%$ e $81,5 \%$ das amostras de swab cloacal de frangos comercializados em açougues de médio e pequeno porte, respectivamente, em Trindade e Tobago.

Resultados de isolamento de Campylobacter em amostras de $s w a b$ cloacal inferiores aos obtidos no presente trabalho, 96,7\% (Tabela 2), foram demonstrados por TRESIERRA-AYLA et al. (1995), que isolaram C. jejuni em $27,00 \%$ de amostras de $s w a b$ cloacal de frangos criados por famílias de baixa condição eco- 
nômica na cidade de Iquitos, Peru. CARVALHO et al. (2001) isolaram, do mesmo modo, Campylobacter spp. em apenas $16,70 \%$ das amostras de swab cloacal coletadas em duas granjas avícolas na região de Ribeirão Preto, SP, e GOMES et al. (2006) isolaram $C$. jejuni em apenas 19,80\% de amostras de swab cloacal coletadas em pequenas propriedades no Município de Pelotas, RS.

A taxa de isolamento de Campylobacter nas amostras da cama, 33,33\% (Tabela 2), foi superior aos resultados encontrados por CARVALHO et al. (2001), $1,8 \%$. Os resultados obtidos para amostras de cama no presente trabalho não estão de acordo com o que afirmaram DOYLE \& ROMAN (1982) e SMITHERMAN et al. (1984), ao justificarem a baixa taxa de isolamento como uma consequência da elevada sensibilidade dessa bactéria às condições adversas da cama de frango para o crescimento bacteriano.

A elevada taxa de isolamento da cama de frango $(33,33 \%)$ (Tabela 2), quando comparada com os resultados obtidos por CARVALHO et al. (2001) (1,8\%), pode ser um reflexo do alto percentual de isolamento das amostras de $s w a b$ cloacal. De acordo com JACOBREITSMA et al. (1995), as aves contaminadas podem liberar de $10^{6}$ a $10^{9} \mathrm{UFC} / \mathrm{g}$ de fezes, disseminando a bactéria para a cama.

Campylobacter não foi isolado em amostras de ração procedentes das granjas pesquisadas (Tabela 2). CARVALHO et al. (2001), no entanto, isolaram a bactéria em $0,60 \%$ de amostras de ração analisadas. Segundo ALTEKRUSE et al. (1999), a ração é uma fonte improvável de Campylobacter, devido à baixa disponibilidade de água para o crescimento da bactéria neste tipo de amostra. Aliado a este fator, as granjas pesquisadas introduziam antibióticos na ração (enramicina, colistina e avilamicina), podendo tal procedimento ter contribuído para o não isolamento de Campylobacter spp. nas amostras de ração.

Campylobacter foi isolado em apenas uma $(3,3 \%)$ amostra de água das granjas pesquisadas (Tabela 2). A amostra de água positiva era proveniente da granja 2, em que o bebedouro era pendular, diferentemente do observado nas duas outras granjas, cujos bebedouros forneciam água por gotejamento. $\mathrm{O}$ bebedouro pendular acumula com facilidade restos de ração, cama, fezes e penas, o que pode ter contribuído para o isolamento de Campylobacter nesse tipo de bebedouro.
CARVALHO et al. (2001) não isolaram a bactéria em nenhuma das amostras de água em granjas avícolas na região de Ribeirão Preto, SP. As três granjas envolvidas neste trabalho realizavam procedimento de cloração da água. Segundo BLASER et al. (1986), há fortes evidências de que os procedimentos de cloração da água sejam eficazes na inativação do Campylobacter.

C. jejuni foi identificado em $82,50 \%$ das cepas isoladas nas granjas estudadas (Tabela 3). Segundo ALLOS \& TAYLOR (1998), C. jejuni e C. coli são as espécies termofílicas mais isoladas em amostras de fezes e C. jejuni é responsável por $80 \%$ a $90 \%$ das infecções.

C. jejuni foi também isolado em $8,7 \%$ das amostras procedentes do abatedouro (Tabela 4), percentual que é cerca de duas vezes maior em relação à taxa determinada por CORTEZ et al. (2006), 4,90\%, em amostras coletadas de diferentes pontos em abatedouros localizados no estado de São Paulo. De modo contrário, CARVALHO et al. (2002) isolaram C. jejuni em elevada taxa, 35,7\%, em amostras coletadas em diferentes pontos da linha de abate em um abatedouro na região nordeste do estado de São Paulo. Essas diferenças de resultados obtidas em diversos estudos podem estar relacionadas aos níveis de controle de qualidade adotados nos estabelecimentos industriais de abate.

No presente trabalho não foi isolado Campylobacter em amostras de fígado coletadas em minitanque de resfriamento do abatedouro (Tabela 4), entretanto, CARVALHO et al. (1997) isolaram C. jejuni em 54,8\% das amostras de fígado coletadas logo após o sacrifício de aves com diarreia em granjas avícolas localizadas na Região de Ribeirão Preto, SP, e CARVALHO et al. (2002) isolaram C. jejuni em 38,0\% das amostras de fígado coletadas logo após a evisceração manual em abatedouro localizado na região Nordeste do estado de São Paulo. Segundo CARVALHO (1998), a coleta de amostras de produtos refrigerados, que foi executada neste trabalho, provavelmente, dificulta o isolamento de Campylobacter.

C. jejuni foi isolado em uma amostra de moela refrigerada coletada no abatedouro (Tabela 4), porém CARVALHO (1998) não isolou a bactéria em amostras de moela refrigeradas comercializadas no município de Jaboticabal, SP. YANG et al. (2003) isolaram C. jejuni em $26,70 \%$ das amostras de moela 
congeladas comercializadas em supermercados no leste da China.

Não foi isolado Campylobacter nas amostras do conjunto de pele do peito e do pescoço (Tabela 4) coletadas logo após a passagem pelo tanque de resfriamento de carcaças. Este resultado não está de acordo com os achados de JORGENSEN et al. (2002), que isolaram a bactéria em $83,0 \%$ das amostras de pele de pescoço em carcaças refrigeradas ou congeladas comercializadas na Inglaterra. Segundo ROSENQUIST et al. (2006), os níveis de contaminação na pele de pescoço aumentam durante o processo de evisceração e declinam após a passagem da carcaça pelo tanque de resfriamento.

Conforme a Tabela 4, C. jejuni foi isolado em $27,8 \%$ das amostras de água coletadas em diferentes pontos do abatedouro. CARVALHO et al. (2002) obtiveram resultados semelhantes ao isolarem a bactéria em $29,70 \%$ das amostras de água coletadas em diferentes pontos da linha de abate em um abatedouro na região nordeste do estado de São Paulo.

C. jejuni não foi, entretanto, isolado nas amostras de água de escaldadeira, o que está de acordo com CORTEZ et al. (2006). Esses autores consideraram que a água de escaldamento à temperatura de $58^{\circ} \mathrm{C}$ diminui a contaminação das carcaças por Campylobacter spp., ainda que não elimine completamente a bactéria. CARVALHO et al. (2002) e CORTEZ et al. (2006) isolaram C. jejuni, respectivamente, em $26,60 \%$ e em $2,8 \%$ das amostras de água de escaldamento.

Das dez $(27,8 \%)$ amostras de água do abatedouro nas quais foi isolado C. jejuni (Tabela 4), quatro amostras eram procedentes da calha de evisceração de carcaças, três da calha de evisceração de moela, duas amostras da calha de evisceração do fígado e uma amostra da calha do conjunto cabeça-pescoço. CARVALHO et al. (2002) isolaram C. jejuni em 61,3\% das amostras de água de evisceração e evidenciaram que esta operação é o principal ponto crítico na disseminação de Campylobacter no abatedouro. CORTEZ et al. (2006) isolaram C. jejuni em apenas 2,8\% das amostras de água de evisceração.

Todas as cepas isoladas no abatedouro foram identificadas bioquimicamente como $C$. jejuni. Segundo PILET et al. (1997), C jejuni é mais frequentemente isolado em relação ao $C$. coli em produtos alimentícios. Em 2000, cerca de 92\% dos isolamentos efetuados pela Unidade de Referência em Campylobacter da Inglaterra foram de C. jejuni (CDSC, 2001).

\section{CONCLUSÃO}

Nas granjas avícolas, a cama, as fezes e, em menor escala, a água foram caracterizadas como as principais fontes de contaminação. No abatedouro, a água de diferentes pontos da calha de evisceração e a moela obtida no minitanque de resfriamento foram os pontos críticos identificados. Entre as cepas isoladas, $C$. jejuni foi identificado em elevado percentual em amostras procedentes das granjas avícolas e em todos os isolamentos do abatedouro.

\section{REFERÊNCIAS}

ALLOS, B.; TAYLOR, D. N. Campylobacter infections. In: EVANS, A. S.; BRACHHMAN, P. S. (Ed.). Bacterial infections of human: epidemiology and control. 3. ed. New York: Phenum Medical Book, 1998. p. 169-170.

ALTEKRUSE, S. F.; STERN, N. J.; FIELDS, P. I.; SWERDLOW, D. L. Campylobacter jejuni: an emerging foodborne pathogen. Emerging Infectious Diseases, v. 5, p. 28-35, 1999.

BAILEY, J. S. Control of Salmonella and Campylobacter in poultry production: a summary of work at Russel Research Center. Poultry Science, v. 72, p. 1169-1173, 1993.

BLASER, M. J.; SMITH, P. F.; WANG, W. L.; HOFF, J. C. Inactivation of $C$. jejuni by chlorine and monochloramine. Applied and Environmental Microbiology, v. 51, p. 307-311, 1986.

BRYAN, F. L.; DOYLE, M. P. Health risks and consequences of Salmonella and Campylobacter jejuni on raw poultry. Journal of Food Protection, v. 58, p. 326-344, 1995.

CARVALHO, A. C. F. B.; SCHOCKEN-ITURRINO, R. P.; CAMA, L. F. S. A. M. Isolation of Campylobacter jejuni from viscera and bile secretion of broiler chickens with diarrhea. Revista de Microbiologia, v. 28, p. 125-128, 1997.

CARVALHO, A. C. F. B. Determinação do NMP de Campylobacter em vísceras comestíveis de frangos refrigerados. Higiene Alimentar, v. 12, n. 55, p. 63-65, 1998.

CARVAlHO, A. C. F. B.; LIMA, V. H. C.; PEREIRA, G. T.; SCHOCKEN-ITURRINO, R. P. Campylobacter em granja avícola. Revista Portuguesa de Ciências Veterinárias, v. 96, p. 191-195, 2001. 
CARVAlHO, A. C. F. B.; LIMA, V. H. C.; PEREIRA, G. T. Determinação dos principais pontos de risco de contaminação de frangos por Campylobacter, durante o abate industrial. Higiene Alimentar, v. 16, n. 540, p. 89-94, 2002.

COMMUNICABLE DISEASE SURVEILLANCE CENTRE CDSC. Campylobacter sentinel surveillancescheme. CDR Weekly, v. 11, 2001.

CORTEZ, A. L. L.; CARVALHO, A. C. F. B.; SCARCELLI, E.; MYASHIRO, S.; VIDAL-MARTINS, A. M. C.; BURGER, K. P. Survey of chicken abattoir for the presence of Campylobacter jejuni and Campylobacter coli. Revista do Instituto de Medicina Tropical de São Paulo, v. 48, n. 6, p. 307-310, 2006.

DOYLE, M. P.; ROMAN, D. J. Sensitivity of Campylobacter jejuni to drying. Journal of Food Protection, v. 45, p. 507-510, 1982.

EVANS, S. J.; SAYERS, A. R. A longitudinal study of Campylobacter infection of broiler flocks in Great Britain. Preventive Veterinary Medicine, v. 46, p. 209-223, 2000.

GOMES, F. R.; CURCIO, B. R.; LADEIRA, S. R. L.; FERNÁNDEZ, H.; MEIRELES, M. C. A. Campylobacter jejuni occurrence in chicken fecal samples from small properties in Pelotas, Southern of Brazil. Brazilian Journal of Microbiology, v. 37, p. 375-378, 2006.

HUNT, J. M.; ABEYTA, C.; TRAN, T. Bacteriological analytical manual. USA: Food and Drug Administration, Center for Food Safety and Applied Nutrition. March, 2001. Chapter 7.

HARTNETT, E.; KELLY, L. A.; GETTINBY, G.; WOOLDRIDGE, M. A quantitative risk assessment for Campylobacter in broilers: work in progress. International Biodeterioretion \& Biodegradation, v. 50, p. 161-165, 2002.

JACOB-REITSMA, W. F.; VAN DE GIESSEN, A. W.; BOLDER, N. M.; MULDER, W. A. W. Epidemiology of Campylobacter spp. at two dutch broiler farms. Epidemiology and Infection, v. 114, p. 413-421, 1995.

JORGENSEN, F.; BAILEY, R.; WILLIAMS, S. HENDERSON, P.; WAREING, D. R.; BOLTON, F. J.; FROST, J. A.; WARD, L.; HUMPHREY, T. J. Prevalence and numbers of Salmonella and Campylobacter spp. on raw, whole chickens in relation to sampling methods. International Journal of Food Microbiology, v. 76, p. 151-164, 2002.

KONEMAN, E. W.; ALLEN, S. D.; JANDA, W. M.; SCHERECKENBERG, P. C.; WINN JR., W. C. Bacilos gram negativos curvos e fermentadores oxidase positivos: Campylobacteriaceae e Vibrionaceae: texto e atlas colorido. 5. ed. Rio de Janeiro: Medsi, 2001.
MACHADO, R. A.; TOSIN, I.; LEITÃO, M. F. F. Occurence of Salmonella spp and Campylobacter sp. In chickens during industrial processing. Revista de Microbiologia, v. 25, n. 4, p. 239-244, 1994.

MEAD, G. C. Microbiological quality of poultry meat: a review. Revista Brasileira de Ciência Avícola, v. 6, n. 3, p. 135-142, 2004.

PILET, M. F.; MAGRAS, C.; CAPPELIER, J. M.; FEDERIGHI, M. La recherche des Campylobacter thermotolerants dans les aliments: méthode de reference et méthode alternatives. Révue de Médecine Vétérinaire, v. 148, n. 2, p. 99-106, 1997.

RODRIGO, S.; ADESIYUN, A.; ASGARALI, Z.; SWANSTON, W. Prevalence of Campylobacter spp. on chickens from selected retail processors in Trinidad. Food Microbiology, v. 22, p. 125$131,2005$.

ROSENQUIST, H.; SOMMER, H. M.; NIELSEN, N. L.; CHRISTENSEN, B. B. The effect of slaughter operations on the contamination of chicken carcasses with thermotolerant. Campylobacter. International Journal of Food Microbiology, v. 108, p. 226-232, 2006.

SALEHA, A. A.; MEAD, G. C.; IBRAHIM, A. L. Campylobacter jejuni in poultry production and processing in relation to public health. World's Poultry Science Journal, v. 54, p. 49-58, 1998.

SAS Institute Inc. SAS/STA software: sintax. Cary NC: SAS Institute Inc., 1993. $151 \mathrm{p}$.

SCOTTER, S. L.; HUMPHREY, T. J.; HENLEY, A. Methods for the detection of thermotolerant campylobacters in foods: results of an inter-laboratory study. Journal of Applied Bacteriology, v. 74, p. 155-163, 1993.

SMITHERMAN, R. E.; GENIGEORGIS, C. A.; FARVER, T. B. Preliminary observations on the occurrence of Campylobacter jejuni at four California chicken ranches. Journal of Food Protection, v. 47, p. 293-298, 1984.

TRESSIERRA-AYLA, A.; FERNADEZ, H.; BENDAYÁN, M. E.; PEREYRA, G.; BERNUY, A. Aislamiento de espécies termotolerantes de Campylobacter em dos poblaciones de pollos criados con y sin confinamiento. Revista de Saúde Pública, v. 29, n. 5, p. $389-392,1995$.

YANG, C.; JIANG, Y.; HUANG, K.; ZHU, C.; YIN, Y. Application of real time PCR for quantitative detection of Campylobacter jejuni in poultry, milk and environmental water. Immunology and Medical Microbiology, v. 38, p. 265-271, 2003. 